\title{
Control Potential of Brassicaceae Cover Crops as Green Manure and their Host Status for Meloidogyne javanica and Criconemoides xenoplax
}

D.H.M. Kruger ${ }^{1}$, J.C. Fourie ${ }^{2}$, A.P. Malan ${ }^{1 *}$

(1) Department of Conservation Ecology and Entomology, Stellenbosch University, Private Bag X1, Matieland, Stellenbosch 7602, South Africa

(2) ARC Infruitec-Nietvoorbij, Private Bag X5026, Stellenbosch 7599, South Africa

Submitted for publication: September 2014

Accepted for publication: December 2014

Key words: Biofumigation, Brassicaceae, cover crop, grapevine, host status, plant-parasitic nematodes

\begin{abstract}
Laboratory bioassays were undertaken to determine the potential of Avena sativa cv. Pallinup (Pallinup oats), Sinapis alba cv. Braco (white mustard), Brassica napus cv. AV Jade (canola), Brassica juncea cv. Caliente 199 (Caliente) and Eruca sativa cv. Nemat (Nemat) to suppress Meloidogyne javanica (root-knot nematode) and Criconemoides xenoplax (ring nematode) when applied as green manure. The host status of the crops also was determined during glasshouse trials. Plant material of the different cover crops was macerated and mixed with nematode-inoculated soil. After a period of 14 and 28 days respectively, susceptible tomato plants were planted in the soil, where they were left to grow in a glasshouse, prior to the performance of a root gall index. The same procedure was followed for $C$. xenoplax, except that, in this case, the nematodes were extracted from the soil after 14 and 28 days to determine the impact of the plant biomass on nematode numbers. To determine the host status of the cover crops concerned, potted plants were inoculated with the two nematode species. Results from the bioassays showed significant suppression of M. javanica by white mustard, Caliente 199 and Nemat. However, no significant differences were found in the $C$. xenoplax bioassays. In the M. javanica glasshouse host trials, Nemat was classified as a poor host. In the $C$. xenoplax host trials, canola was found to have a suppressing effect on $C$. xenoplax. The results are the first to show the effect of biofumigation on $C$. xenoplax nematode.
\end{abstract}

\section{INTRODUCTION}

Plant-parasitic nematode management is complicated by the complexity of the soil, as well as the behaviour of the different plant-parasitic nematode species on different crops (Nusbaum \& Ferris, 1973). The integrated approach to nematode management consists of chemical and biological practices. Due to the conservation pressure on the chemical control options, there is an urgent need for non-chemical alternatives in facilitating the management of soil-borne diseases and nematodes (Gamliel et al., 2000; Lazzeri et al., 2004b). In an integrated approach, the use of resistant cultivars, the choice of cover crops in a crop rotation system, organic matter and the use of green manure play important roles (Barker \& Koenning, 1998; Widmer et al., 2002; Westphal, 2011).

The definition of green manure basically encompasses the incorporation of crop biomass into the soil while the crop is still growing (the green stage), as a supplement to the soil either where it is cultivated onsite, or when it is imported from another site (Pieters, 2006). This practice has been applied for thousands of years. Recent studies have focused on the actual benefit that the follow-up crop can have, after the incorporation of a green manure. In South Africa, cover crops are planted in a rotation system before the planting of the cash crop, or between the grapevine rows. There is also potential for utilising cover crops as part of an integrated approach, before the establishment of perennial crops, in order to make use of biological amendments in suppressing disease complexes such as apple replant disease (Mazzola et al., 2007).

In previous research, various crops have been used, including a wide range of legume, grain and Brassica spp. (Widmer et al., 2002; Pieters, 2006). A well-documented role of green manure is the biocidal effect that it has on soilborne diseases, nematodes and weeds, which is the result of certain biologically active compounds that are released during the maceration and incorporation processes of green manures, with specific reference to Brassicaceae plants and biofumigation (Brown \& Morra, 1997; Sarwar et al., 1998; Lazzeri et al., 2004a; Matthiessen \& Kirkegaard, 2006). The

*Corresponding author: E-mail address: apm@sun.ac.za

Acknowledgements: The authors would like to thank Winetech, Dried Fruit Technical Services and the National Research Foundation of South Africa (NRFTHRIP TP2011060100026), for their funding of the project 
technique, defined as biofumigation, relies on the fumigant action of volatile compounds released during biodegradation for the suppression of plant pathogens (Piedra Buena et al., 2007).

Many different factors, including chemical, physical and biological ones, can have an impact on the efficacy of the fumigation process (Munnecke \& Van Gundy, 1979). The same factors are also involved in the application of green manure to soil, with secondary metabolites being released during the decomposing process of the material to form volatile compounds. Ploeg and Stapleton (2001) found that both time and temperature have an impact on the use of broccoli plant residues against Meloidogyne incognita (Kofoid \& White, 1919) Chitwood, 1949 and Meloidogyne javanica (Treub, 1885) Chitwood, 1949 populations. They found that the application of broccoli to infested soil at relatively high temperatures and for a fairly long period is a good suppressor of nematodes. The lethal dose that is needed to control certain soil-borne diseases declines with a rise in temperature because the distribution of the volatile products is then improved, bearing the other limiting factors in mind (Munnecke \& Van Gundy, 1979). Looking at biofumigation, it is important to realise that the approach is biological in nature, and that the amount of active compounds that are released into the soil is not constant due to cultivation practices, as well as soil and climatic conditions. Green manure that is applied for biofumigation purposes also adds organic matter to the soil, which is an additional benefit to be gained from such use (Roubtsova et al., 2007).

Plant-parasitic nematodes can have a significant impact on most crops. Of the different plant-parasitic nematodes, Meloidogyne spp. (root-knot nematode) is considered to be the most important genus (Nyczepir \& Tomas, 2009). Some of the factors that make this genus so successful as an economically important plant-parasitic nematode include their widespread distribution internationally, their numerous life cycles per season and their wide host range (Nyczepir \& Meyer, 2010). Criconemoides xenoplax (Raski, 1952) Loof \& De Grisse, 1989 (ring nematode), in contrast, is also an economically important plant-parasitic nematode on crops like stone fruit and grapes. Combined with Meloidogyne spp., it is considered to play an important role in peach tree short life disease (Hugo \& Meyer, 1995; Nyczepir et al., 1997). According to Pinkerton et al. (2004), C. xenoplax is widely distributed throughout vineyards in most countries, including the United States of America and Europe. In South Africa, C. xenoplax can produce a negative growth response, as well as reduce grapevine yield (Storey, 2007). In a study conducted by McKenry (1992), it was found that the reduction in grapevine yield of grapes could be between $10 \%$ and $25 \%$ if C. xenoplax numbers exceeded 500 per $\mathrm{kg}$ soil.

Cover crops can play an important role in the suppression of root-knot nematodes, provided they have a poor host status. This may have a negative effect on the development of the nematode population, which can be regarded as indirect suppression of the nematode population. Cover crops, when applied as green manures, can also suppress the nematode species involved. Another aspect that can play a role in the suppression of nematodes, with specific reference to Meloidogyne hapla Chitwood, 1949, is the trap-cropping potential of certain crops (Melakeberhan et al., 2006).

If cover crops are to be incorporated into vineyard soils, the nematode host status of the crops must be known. This will help to ensure that the crops will not cause an increase in the number of specific economically important nematode species that are already present in the soil. The objective of this study was to evaluate the suppressing effect of five cover crops, when applied as green manures to soil infected with $M$. javanica and C. xenoplax in a controlled environment. To determine the host status of both nematode species, the same cover crops were evaluated in glasshouse trials for their host status.

\section{MATERIALS AND METHODS}

\section{Cover crops for green manure application}

Five cover crops, namely Avena sativa cv. Pallinup (Pallinup oats), Sinapis alba cv. Braco (white mustard), Brassica napus cv. AV Jade (canola), Brassica juncea cv. Caliente 199 (Caliente) and Eruca sativa cv. Nemat (Nemat) were selected to determine their potential as green manures for the suppression of M. javanica and C. xenoplax.

In the first bioassays, the cover crop biomass used was grown as part of a field trial executed at Blaauwklippen Estate near Stellenbosch, Western Cape (Fourie et al., 2015). The cover crops were collected at the late flowering, early pod formation stage, with some of the cultivars being slightly later in physiological development stage. In the repeat of the bioassay, the crop biomass was grown in pots at $25 \pm 2{ }^{\circ} \mathrm{C}$. Seeds from the five cover crops were sown in six $4 \mathrm{~L}$ black plastic growing bags. The plants were fertilised on a weekly basis with Chemicult ${ }^{\circledR}$, consisting of a balanced N.P.K. ratio, as well as with micronutrients. The plants were watered by means of irrigation on a daily basis.

\section{Experimental procedure followed for laboratory bioassays}

The experimental methods for the laboratory bioassays were based on a protocol described by Piedra Buena et al. (2006). The method was developed by the Agro-ecology Department of Centro de Ciencias Medioambientales (CCMA), Consejo Superior de Investigaciones Cientificas (CSIC), Madrid, Spain.

\section{Experimental procedure followed to determine host status}

The glasshouse trial, to determine the host status, consisted of the five cover crop species, with a tomato as control. For each host there were 10 replicates. After the plants had been grown for approximately 40 days, they were either inoculated with the eggs of $M$. javanica, or soil-infested with C. xenoplax, according to a predetermined concentration.

\section{Meloidogyne javanica inoculum}

Tomato plants inoculated with eggs of $M$. javanica were grown in a glasshouse for four months. To obtain the eggs, the roots were carefully removed from the soil. After being washed and cut up into $2 \mathrm{~cm}$ pieces, they were immersed in $250 \mathrm{ml}$ of $0.5 \%$ sodium chloride solution $(\mathrm{NaOCl})$, which was added to a $500 \mathrm{ml}$ Schott bottle and shaken vigorously for $4 \mathrm{~min}$ (Hussey \& Barker, 1973). The contents of the 
bottle were then passed through a $75 \mu \mathrm{m}$ pore (200 mesh) sieve, nested within a $38 \mu \mathrm{m}$-pore sieve (500 mesh), and thoroughly rinsed with a stream of water. The eggs that were collected on the $38 \mu \mathrm{m}$ pore sieve were washed into a beaker. The roots were returned to the bottle, to which water was added, whereupon the process was repeated. The nematode egg concentration was determined using the technique described by Navon and Ascher (2000). Five $10 \mathrm{ml}$ drops of a suspension of nematodes in a specific volume were placed on a glass slide, and the number of nematodes were counted in $50 \mu 1$. This was repeated five times, with the volume of water being diluted to the concentration used as inoculum.

\section{Criconemoides xenoplax inoculum}

The peach rootstock Atlas, established in $25 \mathrm{~L}$ plastic pots, was inoculated with C. xenoplax approximately 24 months before the start of the trial. The plants were kept in a glasshouse at a temperature of $<25^{\circ} \mathrm{C}$. A soil auger was used to take a $100 \mathrm{ml}$ soil sample from the roots of these pots. The method of Jenkins (1964) was followed to extract nematodes from the soil and the concentration was estimated by counting two aliquots of $1 \mathrm{ml}$ in a counting chamber.

\section{Effect of green manure on Meloidogyne javanica}

A total of $700 \mathrm{~g}$ sterilised medium, consisting of bark and sand, was added to sealable plastic bags. The medium was inoculated with $1000 \mathrm{M}$. javanica eggs, and mixed to obtain an even distribution of the eggs in the medium. The green manure (biomass of the cover crops) was added to the inoculated medium. The control treatment was inoculated with only nematode eggs, without the addition of green manure. Ten bags were used in each treatment. A total of 30 g of cover crop plant material, consisting of roots, stems and leaves in $75 \mathrm{ml}$ of water, was macerated in a food blender for 10 seconds. The plant material was then added to the inoculated medium in the plastic bags. The content of the bags was mixed and left in a growth chamber at $25^{\circ} \mathrm{C}$ for 14 days, after which it was placed in pots to which susceptible tomato plants were added. The pots were placed in a completely randomised design in a glasshouse kept at $25^{\circ} \mathrm{C}$. After 80 days, the experiment was terminated, whereupon each plant was carefully removed and the roots were rinsed off with water. Each root system was inspected and a root galling index was used to determine the amount of $M$. javanica infestation that was present in the roots. This gall evaluation was done on a scale of 0 to 5 , as adapted from the technique used by Hussey and Janssen (2002), where $0=$ no galls, $1=1$ to 10 galls, $2=10$ to 50 galls, $3=50$ to 100 galls, $4=>100$ galls, and $5=$ covered with galls.

The same protocol was followed during the repeat bioassay. A total of $30 \mathrm{~g}$ green manure was used, collected during the flowering and early pod formation stage and consisting of leaves and stems. The pots were left to grow for 142 days and then evaluated for root gall formation on the tomato roots. The duration of this period was longer than was suggested in the protocol, but, as root gall formation had not yet taken place in the control pots, the decision was made to leave the plants until sufficient root gall formation could be evaluated in the control treatment.

\section{Effect of green manure on Criconemoides xenoplax}

The soil used for the C. xenoplax bioassay was first collected at the field trial site, and then sieved and heat sterilised $\left(55^{\circ} \mathrm{C}\right.$ for $\left.24 \mathrm{~h}\right)$. A total of $500 \mathrm{~g}$ of the sterilised medium was then placed in sealable plastic bags. A total of $200 \mathrm{ml}$ of the growing medium, representing an estimated amount of 2500 C. xenoplax juveniles, was placed in the same plastic bags and mixed thoroughly. Six treatments were undertaken, consisting of five cover crops and one control crop. The green manure was added to the inoculated medium. The control treatment consisted of sterilised medium, inoculated with the C. xenoplax only, without green manure.

Plant material (10 g), consisting of roots, stems and leaves, was macerated using scissors. It was then added to the plastic bags containing the sterilised medium and C. xenoplax. Water $(25 \mathrm{ml})$ was added to the plastic bags. The plastic bags were then placed in a temperature- controlled chamber at $25^{\circ} \mathrm{C}$ for 14 days, after which the evaluation was done using the same extraction technique as described above, with $250 \mathrm{ml}$ of soil. There were five replicates of each treatment.

In the second bioassay, sterilised medium, consisting of bark and sand, was used as the medium for the inoculation of C. xenoplax. A total of $600 \mathrm{~g}$ of the sterilised medium was placed in sealable plastic bags. A total of $75 \mathrm{ml}$ water was added to the medium before inoculation with the nematodes. Thereafter, $100 \mathrm{ml}$ of growing medium, representing 2500 C. xenoplax, was placed in the same plastic bags and mixed thoroughly. The same treatments were conducted as in the first bioassay, but with 10 repetitions per treatment. Plant biomass, consisting of leaves and stems, was harvested after approximately two months. During the flowering, early pod formation stage, $30 \mathrm{~g}$ of the plant material was cut into fine pieces, each smaller than $1 \times 1 \mathrm{~cm}$, in a food processor for approximately 10 seconds, and then applied to the $600 \mathrm{~g}$ of inoculated medium. The cut-up green plant material was mixed thoroughly with the inoculated soil. The bags were then placed in a temperature-controlled chamber at $25^{\circ} \mathrm{C}$ for 28 days. Afterwards, the C. xenoplax numbers present were determined using the same extraction technique described above.

\section{Host status of cover crops for Meloidogyne javanica}

To determine the susceptibility of the different cover crops to M. javanica, seed was sown directly in growing bags filled with $700 \mathrm{ml}$ sterilised medium and left to grow for 40 to 60 days. In the first trial, $4 \mathrm{~L}$ growing bags were used, whereas in the second trial, $700 \mathrm{ml}$ growing bags were used. Ten replicates of each cover crop and tomato were inoculated with $4000 \mathrm{M}$. javanica eggs in trial 1, and with 1000 eggs in trial 2. In both trials, the plants were left to grow for 60 days before a root gall evaluation was conducted.

\section{Host status of cover crops for Criconemoides xenoplax}

The same trial layout as described for M. javanica was used for C. xenoplax. In the first trial, $200 \mathrm{ml}$ of soil, representing 2500 C.xenoplax, was used to inoculate the plants. The crops were grown for 85 days before the $C$. xenoplax evaluation was undertaken. In the second trial, the $700 \mathrm{ml}$ growing bags that were used to grow the cover crops were inoculated with 
$100 \mathrm{ml}$ of medium, representing 2500 C. xenoplax. In each trial, the bags inoculated only with $C$. xenoplax, without any cover crop, were included. An additional control treatment, using tomato plants as the host, was also inoculated with C. xenoplax. Following the inoculation, the plants were grown for 92 days, after which the evaluation was done.

\section{Evaluation of Meloidogyne javanica host status}

After the termination of the experiment, each plant was carefully removed from the bags and the roots were rinsed with water. Each root system was carefully inspected, and a root galling index was used to determine the amount of $M$. javanica infestation present in the roots. This gall evaluation was done on a scale of 0 to 5 , as described earlier. According to the mean gall classification, the cover crops were then classed as good hosts, maintenance hosts or poor hosts for $M$. javanica. A classification of between 0 and 2 indicated a poor host, between 2 and 4 indicated that they could be used as maintenance crops, and between 4 and 5 indicated good host status. The root systems were inspected visually using a Leica MZ7 stereo microscope that was fitted with a camera to determine the formation of egg masses. The egg masses were then removed and left for $24 \mathrm{~h}$ in a glass crucible to determine their hatching.

\section{Evaluation of Criconemoides xenoplax host status}

The soil from each plant was carefully shaken from the roots and thoroughly mixed. Of the soil, $250 \mathrm{~cm}^{3}$ was washed using the same sugar flotation technique (Jenkins, 1964) for determining the inoculum concentration as described previously. The number of nematodes present was then counted.

\section{Statistical analyses}

All the laboratory experiments conducted were repeated on different test dates. All statistical analyses were performed using the STATISTICA (ver. 10) data analysis software system (StatSoft, Inc., 2011). The data obtained from the bioassays was analysed using an analysis of variance (ANOVA), regarding the trial test date and relevant treatments as separate factors. If the data were not normally distributed, a non-parametric analysis, using the KruskalWallis test, was performed.

\section{RESULTS}

\section{Meloidogyne javanica bioassays}

When the results were analysed using a two-way ANOVA, no significant differences $\left(\mathrm{F}_{(5,108)}=1.800 ; \mathrm{p}=0.118\right)$ were found between the main effects (date and treatment). Results from the two trial dates were then pooled and analysed, using a one-way ANOVA, with significant differences $\left(F_{(5,108)}=3.862 ; p<0.005\right)$ found among the treatments.

No significant differences were found between the root gall index of oats, canola and the control (Fig. 1). All three crops obtained an average gall index of approximately 3 , with between 50 to 100 galls each. White mustard $(\mathrm{p}=0.0188)$, Caliente $(\mathrm{p}=0.0248)$ and Nemat $(\mathrm{p}=0.0188)$ had significantly lower gall indexes than canola. White mustard, Caliente and Nemat did not differ significantly from one another, and neither were there any significant differences between the three treatments concerned and the Pallinup oats treatment.

\section{Criconemoides xenoplax bioassays}

No significant differences were found when the main effects were interpreted $\left(\mathrm{F}_{(5,78)}=0.746 ; \mathrm{p}=0.591\right)$. There also were no significant differences between the various treatments involved $\left(\mathrm{F}_{(5.78)}=0.463 ; \mathrm{p}=0.802\right)$ (data not shown).

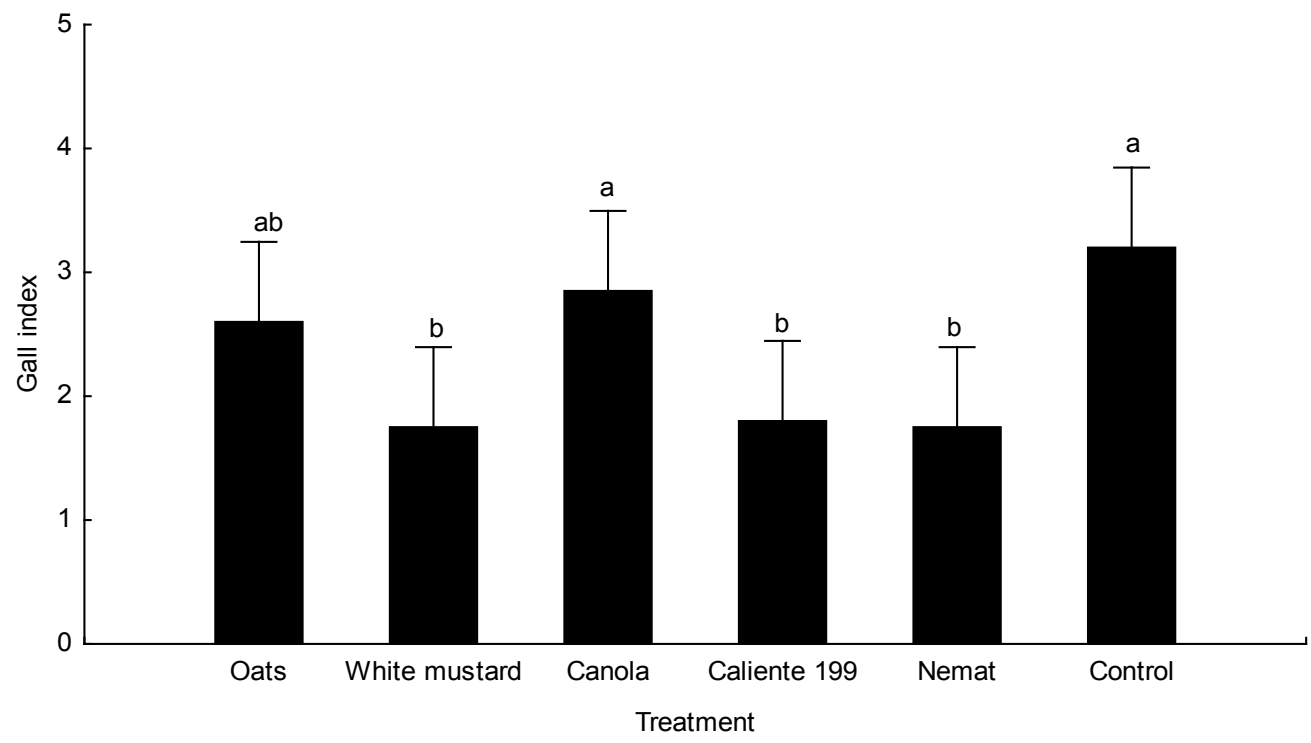

FIGURE 1

Meloidogyne javanica gall index (95\% confidence interval) on tomato, treated with green manure of five different cover crops: oats (Avena sativa cv. Pallinup), white mustard (Sinapis alba cv. Braco), canola (Brassica napus cv. AV Jade), Caliente 199 (Brassica juncea cv. Caliente 199), and Nemat (Eruca sativa cv. Nemat), incorporated into M. javanica-inoculated soil (oneway ANOVA; $\left.\mathrm{F}_{(5,108)}=3.862 ; \mathrm{p}<0.005\right)$. Bars with the same letter did not differ significantly. 


\section{Host status of cover crops for Meloidogyne javanica}

No significant difference $\left(\mathrm{F}_{(5,104)}=2.155 ; \mathrm{p}=0.065\right)$ was found between the interaction effects (test date and galling) when they were analysed using a two-way ANOVA. On pooling and analysing the data from the two trial dates using a one-way ANOVA, however, significant differences were found among the treatments $\left(\mathrm{F}_{(5,110)}=64.454 ; \mathrm{p}<0.005\right)$ (Fig. 2).

All the cover crops differed significantly $(\mathrm{p}<0.05)$ from the tomato control regarding their host status for $M$. javanica, with the control resulting in a severe expression of galls on the roots with a gall index of 5 (Fig. 4). The gall index for Pallinup oats was significantly lower than that of canola $(p<0.01)$ and Caliente $(p=0.01)$, but it did not differ significantly from white mustard $(\mathrm{p}=0.4)$ or Nemat $(\mathrm{p}=0.8)$. Nemat was significantly lower in its $M$. javanica gall expression than the other crops, except for oats.

\section{Visual inspection of the different root systems}

The root systems, as well as the gall and egg mass formation on the roots of the different crops, are depicted in Fig. 3. The root gall symptoms on the canola roots were very prominent, being comparable to the symptoms on the control roots. The egg masses were prominent, with the distribution of the symptoms being uniform throughout the root system. The females, which were well embedded in the root system, were enclosed by the root cells.

Prominent root galls and egg masses were also present in the root system of Caliente. The females, which were deeply embedded in the root system, were well protected by the root cells. Fewer galls were present on the total root system of the oats, with the galls that were present being less prominent and more like a slight enlargement of the root tissue. The female body was not totally embedded in the
Pallinup oats root system, with a part of the body still being visible outside the root. The egg masses were more visual than were the galls on the roots. The distribution of the egg masses was not uniform throughout the root system, seeming to be situated closer to the soil surface. Very few galls or egg masses were present on the root system of the Nemat. The galls that were present were only a slight enlargement of the root tissue, with few egg masses showing on the roots. Fewer galls and egg masses were present on the roots of the white mustard in comparison with those that were present on the Caliente and on the canola, with the distribution throughout the root system not being uniform. The females were not fully embedded in the root system, although they were more protected in comparison with the females that were present in the oats treatment. The roots of the control plants were totally covered with galls and the egg masses were very prominent.

\section{Host status of cover crops for Criconemoides xenoplax}

No significant difference $\left(F_{(5,107)}=1.075 ; p=0.105\right)$ was found between the interaction effects (test date and treatment) when the analysis was undertaken by means of a two-way ANOVA. When the results from the two trial dates were pooled and analysed using a one-way ANOVA, significant differences $\left(\mathrm{F}_{(6,122)}=8.233 ; \mathrm{p}<0.005\right)$ were found among the treatments (Fig. 4).

The tomato treatment had significantly higher $(\mathrm{p}<0.01)$ C. xenoplax numbers than the other treatments, except for Nemat (Fig. 4). The C. xenoplax numbers in the cover crops did not differ significantly from the control (soil only). Canola had the least C. xenoplax at the time of evaluation, with the number concerned being significantly lower than that of Nemat $(p=0.003)$.

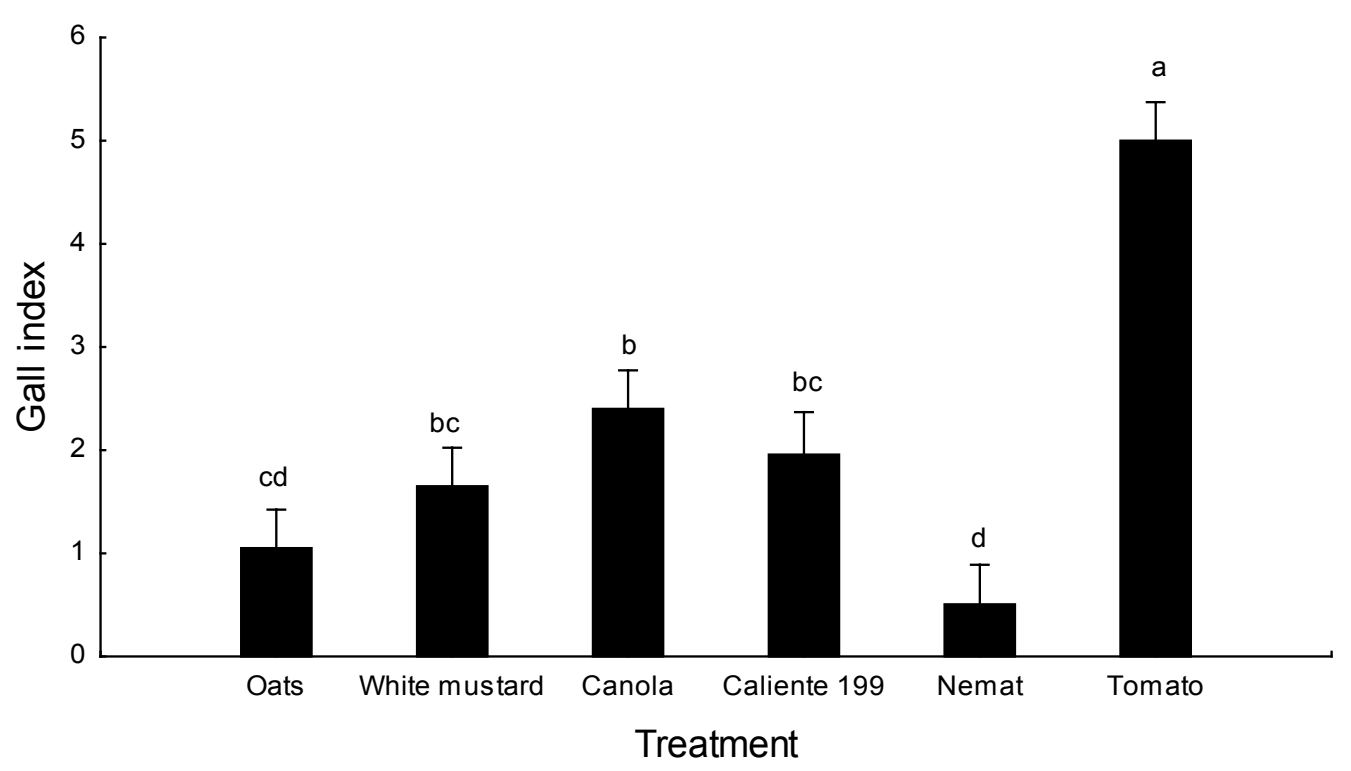

FIGURE 2

Gall index of Meloidogyne javanica (95\% confidence interval) 60 days after inoculation of five different cover crops: oats (Avena sativa cv. Pallinup), white mustard (Sinapis alba cv. Braco), canola (Brassica napus cv. AV Jade), Caliente 199 (Brassica juncea $\mathrm{cv}$. Caliente), Nemat (Eruca sativa cv. Nemat), and tomato as control (one-way ANOVA; F ${ }_{(5,104)}=68.919 ; \mathrm{p}<0.05$ ). Bars with the same letter did not differ significantly. 


\section{DISCUSSION}

In the current study, the three brassica crops, namely white mustard, Caliente and Nemat, were found to suppress $M$. javanica gall formation when applied as green manure. This correlates well with previous studies, in which in vitro tests showed that, in most cases, a reduction of nematodes occurs with the application of brassica crops as green manure in comparison with the application of non-brassica crops (Mojtahedi et al., 1993). The effect involved is most probably due to the GSL in the tissue of the brassicas (Brown $\&$ Morra, 1997). The formation of the active ingredients, with the most emphasis on the ITC, was believed to give the suppressant effect required (Lazzeri et al., 1993). An example of such an experiment was that of McLeod and Steel (1999), in which different Brassica cultivars were sown during two different sowing periods. In both trials the $10 \mathrm{~g}$ and $20 \mathrm{~g}$ application rates significantly reduced the number of nematodes recovered. The nematode-suppressing effect of different crops, after their incorporation into the soil, can differ drastically between crops, however, with not all crops having the potential to be utilised in this manner (McLeod \&
Steel, 1999; Piedra Buena et al., 2006).

Rahman et al. (2009) performed a trial with oneyear-old Semillon grapevines planted in pots, which were inoculated with $500 \mathrm{M}$. javanica larvae after three months and then left for six months. Annually for three consecutive years, the brassica seeds that were sown under the vines were slashed after three months and then incorporated into the soil. The results indicate a gradual decline in the $M$. javanica population in the pots, with the best results being obtained in the third year. The vines in the pots that received the green manure also experienced a growth response, indicating the secondary effect of the green manure applications. Stirling and Stirling (2003) sowed brassicas in field soil and incorporated the green material into the soil at a depth of 180 $\mathrm{mm}$ after 10 weeks. A root gall index indicated a significant reduction in the $M$. javanica root galls where brassicas were incorporated at an earlier stage.

In the current study, the canola treatment did not show the same response to $M$. javanica with regard to the root gall index as did the other brassica species. Different types and concentrations of GSL were found to be present in the
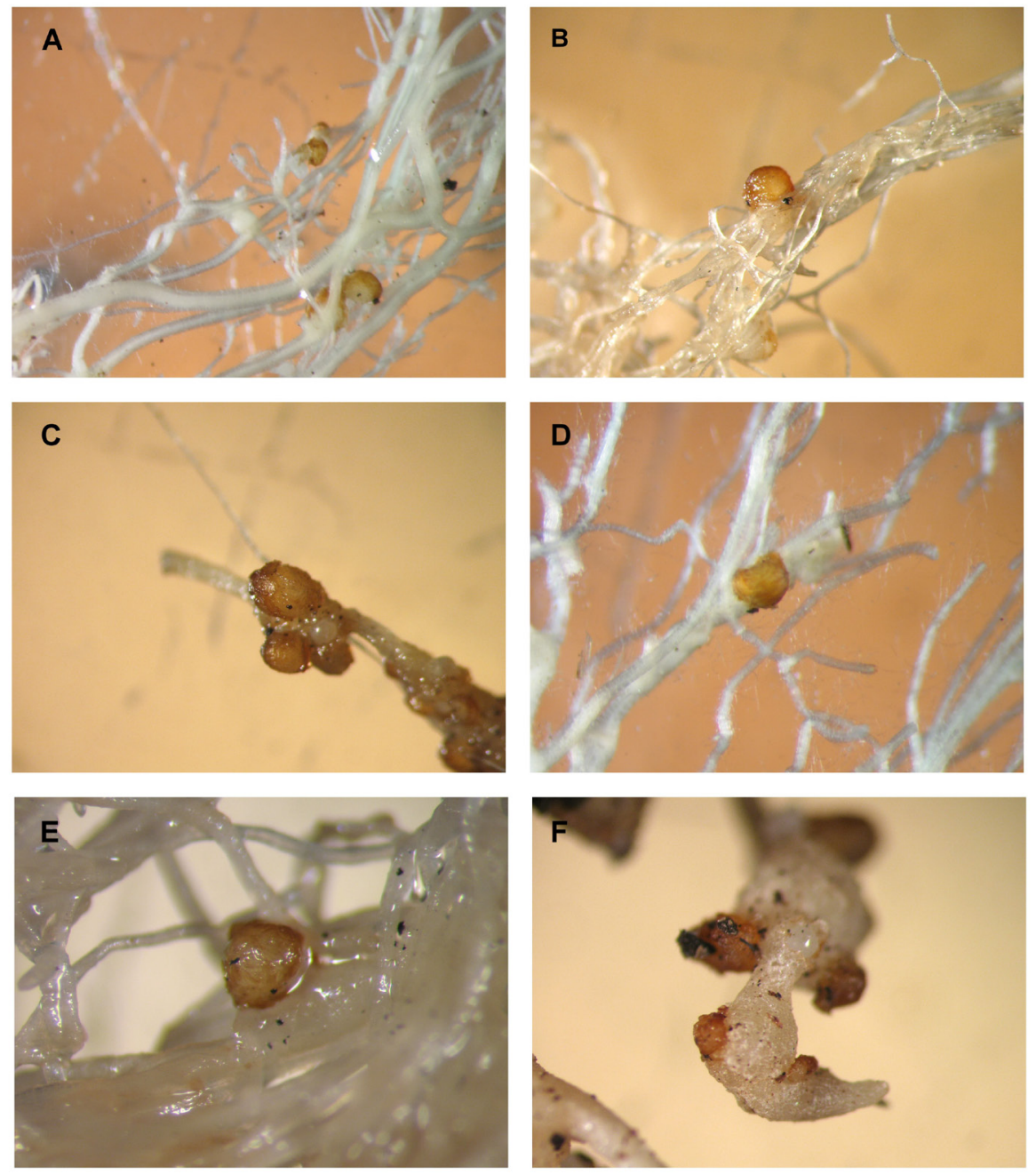

FIGURE 3

Meloidogyne javanica galls and egg masses present on the different crop roots. A = canola (Brassica napus cv. AV Jade); $\mathrm{B}=$ Caliente (Brassica juncea cv. Caliente 199); C = oats (Avena sativa cv. Pallinup); D = Nemat (Eruca sativa cv. Nemat); E = white mustard (Sinapis alba cv. Braco); tomato (Moneymaker). 


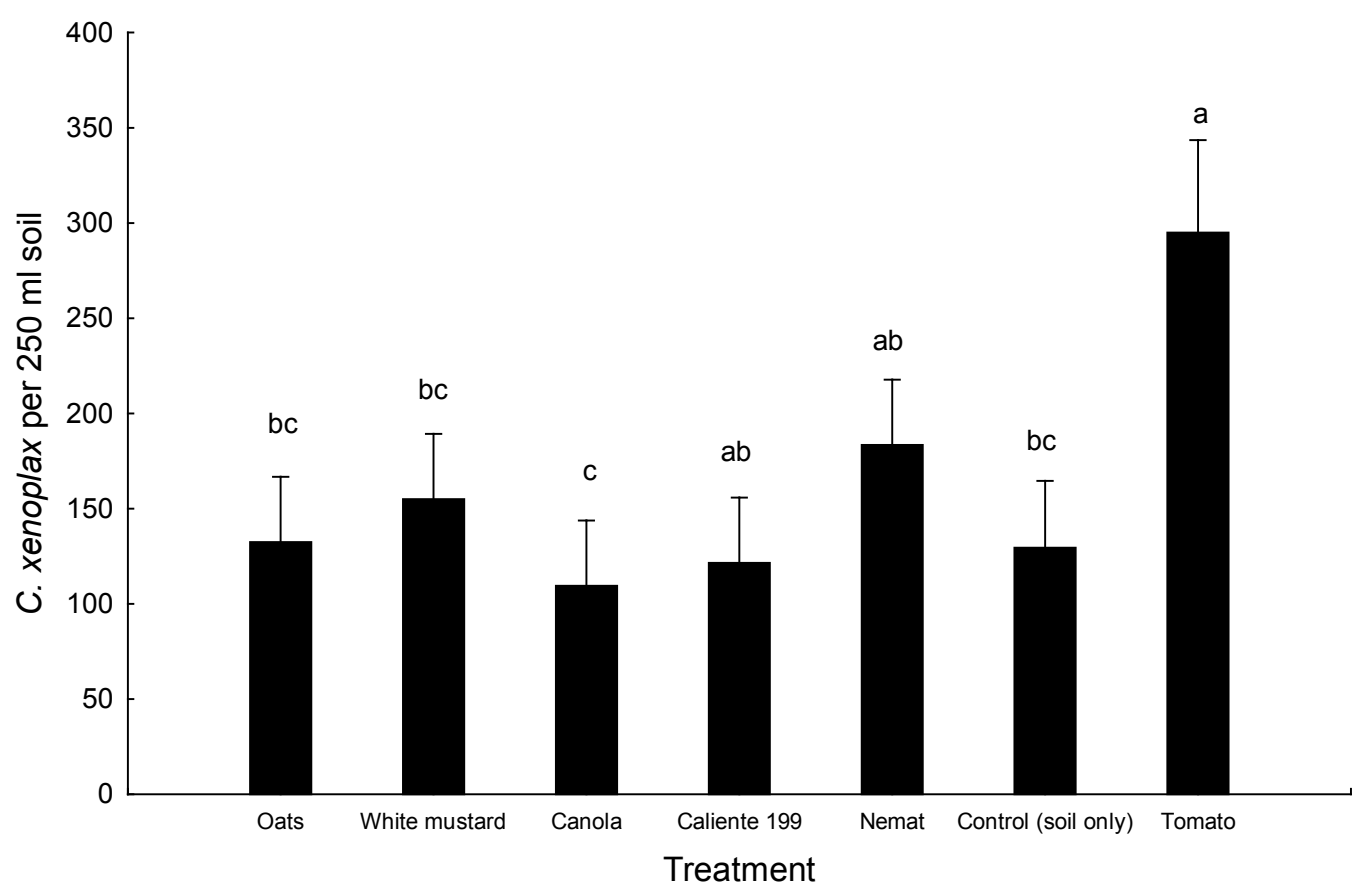

FIGURE 4

Criconemoides xenoplax numbers (95\% confidence interval) on five different cover crops, oats (Avena sativa cv. Pallinup), white mustard (Sinapis alba cv. Braco), canola (Brassica napus cv. AV Jade), Caliente 199 (B. juncea cv. Caliente 199), and Nemat (Eruca sativa cv. Nemat), 60 days after inoculation with nematodes. Inoculated soil was used as control, and tomato crops were used as an additional treatment (one-way ANOVA; $\mathrm{F}_{(6,122)}=8.2325 ; \mathrm{p}<0.005$ ). Bars with the same letter did not differ significantly.

different brassica crops, with the canola not being considered to have a very active composition of GSL. Therefore it can be expected that canola crop residues would not have the same biofumigation effect on $M$. javanica as would the other brassica species, known for the active biocidal role that they play when they are applied for the purposes of biofumigation. The results obtained in this study support previous work undertaken and will promote the green manuring of these species as part of an integrated approach for Meloidogyne spp. suppression in the field.

The fact that there was no significant difference in the $C$. xenoplax population where the crop residues were applied to the inoculated medium indicates that, in these specific bioassays, biofumigation cannot be considered to be as effective in suppressing C. xenoplax. It is important, however, to note that the dose response must be taken into consideration with biofumigation. Future research should consider the application of higher concentrations of biomass. For any fumigation action to be successful, the key factors of contact time and concentration must be considered. The enhancement of such factors potentially could have a more positive impact on the suppression of $C$. xenoplax than that reported in the current study. Criconemoides xenoplax also, in general, are considered to be more difficult to control than most of the other plant-parasitic nematodes. One of the reasons for such difficulty is the thick cuticle of the nematode, which gives it its descriptive name and which makes the contact action of most control measures a challenge. The ITC concentration that will be needed to suppress $C$. xenoplax effectively can also be expected to be higher than the concentration that is needed to suppress the M. javanica, because of the above-mentioned factors.

Much research has been done on the specific type of GSL that is present in certain brassica species, as well as the types of ITC that are formed following the MYR-GSL reaction (Sarwar et al., 1998; Gimsing \& Kirkegaard, 2006). Research has also been conducted on the efficacy of biofumigation on Meloidogyne spp. suppression (Lazzeri et al, 2004a; 2004b; Riga \& Collins, 2004). In future research it would be advantageous if a specific lethal concentration could be determined for the constant effective suppression of the Meloidogyne species. In addition, it would be useful to determine the lethal concentration of ITC that is likely to be effective in the continuous suppression of C. xenoplax, bearing in mind all the above-mentioned factors that can play a role in effective biofumigation.

In the $M$. javanica host trials, the control gall index was significantly higher than it was in the case of the rest of the cover crops tested. This was to be expected, as the tomato cultivar that was chosen for this study is not known to be resistant to $M$. javanica, thus making it suitable as a control treatment. The gall symptom expression on the tomato plants, which was also very severe, gave a good impression of what a crop looks like when it is heavily infected with $M$. javanica. The use of these plants exemplifies what can occur in terms of the impact of the wrong crop planted as part of a crop rotation, in intercropping, or in a crop rotation system on an $M$. javanica population, as such a crop can host the full development of the latter's life cycle and also cause a population build-up in the soil. 
The results that were obtained in this study indicate that all cover crops tested were hosts for M. javanica, as galling, egg mass production and egg hatching were observed on all the cultivars. However, the severity of the infection, as well as the expression of the symptoms, differed among the cultivars, with differences occurring in the $M$. javanica population build-up where these cover crops were planted. The gall index of Nemat was less than 1 and significantly lower than that of the other brassica crops. Nemat therefore can be classified as a poor host for $M$. javanica. Nemat is also known as a trap root host (Melakeberhan et al., 2006). In the current study, however, $M$. javanica did complete its life cycle, and Nemat did not act as a catch crop in respect of preventing the development of a new generation.

Melakeberhan et al. (2006) showed that Nemat reduces the development and reproduction of M. hapla in pot trials, where the evaluation was based not only on the presence of root galls on the roots, but also on the suppression of all the developmental stages of M. hapla. The studies also showed that there was a limiting effect on the development of the females, and thus in their reproduction on Nemat roots, resulting in no production of eggs. The current study indicated Nemat to be a poor host for M. javanica, which could have a significant suppressing impact on the population development in the field. In addition, Curto et al.'s (2005) study showed that Nemat reduced $M$. incognita reproduction due to the interruption of the life cycle, or to the slowing down of the reproduction rate. The potential therefore exists for Nemat to be used in an integrated root-knot nematode management approach as a trap crop and also to make a positive contribution through biofumigation (Curto et al., 2005).

The other three brassica species, being white mustard, canola and Caliente, did not differ significantly from one another, with all three having a low root gall index. The three crops involved therefore can be classified as maintenance crops for $M$. javanica. These results correlate with the work that was done by Curto et al. (2005). In the latter study, certain Brassicaceae and Capparaceae crops were selected and tested for their crop host status for M. incognita. The results indicated that Rapistrum rugosum sel. ISCI 15, Nemat, Barbare averna sel. ISCI 50, and Raphanus sativus cv. Boss can all be classified as poor to non-hosts, while Brassica juncea sel. ISCI 99 is classified as a maintenance crop, and B. juncea sel. ISCI 20, Lepidium campestre sel. ISCI 103 and Erucastrum gallicum are classified as good hosts for M. incognita.

The reproduction of $M$.javanica on certain brassica crops was compared to that on other crops that were not known to have biofumigation properties (Stirling \& Stirling, 2003). The crops that were included in these trials were $B$. juncea cv. Nemfix (Indian mustard), B. napus cv. Dunkeld (canola), B. napus cv. Rangi (rape), Sorghum bicolor $\times$ Sorghum Sudanese cv. Jumbo (forage sorghum), and L. esculentum cv. Tiny Tim (tomato). It was found that the brassica crops were hosts (maintenance crops) for M.javanica, but that they were significantly less so than were the tomato plants. Together with the forage sorghum, the number of eggs present in the case of the brassica crops was the lowest of all the crops considered. These results are all comparable with the results that were obtained in the current study.

Canola, although not significantly different from Caliente and white mustard, was found to have the highest gall index rating of the brassica crops. It therefore could sustain a population build-up of $M$. javanica better than the other brassica crops over the medium to longer term. Canola is considered to be a poor biofumigation crop because of the impact of its GSL spectrum on its root susceptibility. Also, canola has a lower biofumigation potential when it is applied as a biofumigation crop. The fact that canola therefore is not seen as the best option for the suppression of $M$. javanica must be taken into consideration when the exact aims of the cover crop programme employed are determined.

Although Pallinup oats is not a brassica crop, it is widely accepted that the species has a poor host status for a wide range of soil-borne problems, including $M$. javanica. This was confirmed in the current study, as Pallinup oats showed the second lowest root gall index of the crops studied and did not differ significantly from the Nemat treatment. However, Pallinup oats cannot be classified as a non-host, or as a trap crop, as root gall formation and egg mass production occur on the roots. It is clear, from a cover crop or rotation crop perspective with a focus on $M$. javanica population suppression, that oats is a viable option, and that it can be used as part of a cover crop rotation programme without the risk of stimulating the $M$. javanica population in the soil where it is planted.

The results obtained in this study indicate that Nemat and Pallinup oats can be used successfully as part of an IPM programme to help suppress the population buildup of $M$. javanica in the soil. The crops concerned can be considered as cover crops for perennial crops, as rotation crops in terms of annual crops like vegetables, or for use in an intercropping system. In terms of the latter application it is important to bear in mind that other aspects, such as nutrition competition, might play a role. The above-mentioned factors are all focused on the crop host status and on the trap crop effect of Nemat, although there also is a possibility of implementing Nemat as a biofumigation crop. By means of such implementation, a three-way positive impact could be achieved: 1) the impact that the cover crop host status has on preventing a population build-up, as discussed above; 2) a direct $M$. javanica suppression effect, resulting from the biofumigation effect; and 3) the secondary effect that the application of the green manure biomass can have on the general health and biodiversity of the soil when it is applied as a biological soil amendment.

The practical application of the cover crop used (in terms of planting, slashing and incorporation) should be implemented before the planting of the next cash crop (with the slashing and incorporation taking place at least 21 days before the planting of the follow-up crop) to help reduce the population of $M$. javanica during the growing period and through biofumigation following incorporation. Doing the above would also help to decrease the pressure on chemical nematicide application. The potential also exists for combining Nemat and chemical fumigation. In the work done by Riga (2011), a significant reduction was achieved in a Meloidogyne chitwoodi Golden, O’Bannon, Santo \& Finley, 1980 population, where Nemat was used in combination 
with a soil fumigant at a lowered rate, in comparison with using Nemat alone. The best results were still obtained by using the soil fumigant alone at the full registered dose rate.

Of all the cover crop treatments in the current study, the C. xenoplax numbers were found to be the highest in Nemat, and significantly higher than that which occurred in the canola treatment. However, no significant difference was found between Nemat and the soil-alone treatment, indicating that even though the Nemat tended to increase the $C$. xenoplax population, such an increase does not necessarily indicate that Nemat is a good host for C. xenoplax, but rather that it can be classified as a maintenance crop for $C$. xenoplax. A positive trend to emerge from the data is the fact that the canola treatment resulted in the lowest number of $C$. xenoplax, thus enabling it to be classified as a poor host for the nematode concerned. It can be expected that, if canola is planted as part of a cover crop system, it will neither stimulate a $C$. xenoplax population build-up, nor will it maintain the population, but it rather will have a suppressing effect on the population. In this regard, Caliente, Pallinup oats and white mustard show a similar, but weaker, trend.

\section{CONCLUSIONS}

A well-planned rotation programme in which different crops, with a variety of characteristics, are rotated with one another is widely accepted as having a suppressing effect on a wide range of economically important soil-borne diseases, plantparasitic nematodes and weeds. A characteristic that is very important to bear in mind in this regard is the host status of the specific crop. Whether it is applied as a cover crop in vineyards or orchards during the dormant stage of the crop, as a rotation crop in a cash-cropping system, or used prior to the replanting of trees where the replant disease complex plays a role, the host status of the crop used is a critical factor for breaking the life cycle of certain soil-borne biotic problems. The use of Nemat as a cover or rotation crop can be beneficial in suppressing $M$. javanica. In the case of C. xenoplax, one can expect to see a decline in the population over time when canola is implemented in terms of a cover crop system.

Biofumigation, which is a definite option as part of an integrated approach to nematode management, can be implemented as part of a rotation system, as part of cover crop systems, and as a biological alternative in combination with certain chemical options. The biological interactions that take place when incorporating green manure also form a very beneficial aspect, which in itself can have a positive secondary impact on the suppression of plant-parasitic nematodes by means of the stimulation of biological diversity. As cover crops can play a very important role in IPM, it would be beneficial in future research to consider the crop host status for most cover crops that form part of cover crop or rotation systems, as well as to look at the possibility of combining such considerations with other chemical and biological options in establishing a long-term solution for nematode management.

\section{LITERATURE CITED}

Barker, K.R. \& Koenning, S.R., 1998. Developing sustainable systems for nematode management. Ann. Rev. Phytopathol. 36, 165-205.
Brown, P.D. \& Morra, M.J., 1997. Control of soilborne plant pests using glucosinolate-containing plants. Adv. Agron. 61, 167-231.

Curto, G., Dallavalle, E. \& Lazzeri, L., 2005. Life cycle duration of Meloidogyne incognita and host status of Brassicaceae and Capparaceae selected for glucosinate content. Nematol. 7, 203-212.

Fourie, J.C, Kruger, D.H.M. \& Malan, A.P., 2015. Effect of management practices applied to cover crops with bio-fumigation properties on cover crop performance and weed control in a vineyard. S. Afr. J. Enol. Vitic. 36, 146-153.

Gamliel, A., Austerweil, M. \& Kritzman, G., 2000. Non-chemical approach to soilborne pest management - organic amendments. Crop Protec. 19, 847853.

Gimsing, A.L. \& Kirkegaard, J.A., 2006. Glucosinolate and isothiocyanate concentration in soil following incorporation of Brassica biofumigants. Soil Biol. \& Biochem. 38, 2255-2264.

Hugo, H.J. \& Meyer, A.J., 1995. Severe nematode damage to peach trees in South Africa. Nematol. 41, 310

Hussey, R.S \& Barker, K.R., 1973. A comparison of methods for collecting inocula of Meloidogyne spp. including a new technique. P1. Dis. Rep. 57,1025-1028.

Hussey, R.S. \& Janssen, G.J.W. 2002. Root-knot nematodes: Meloidogyne species. In: Starr, J.L., Cook, R. \& Bridge, J. (eds). Plant resistance to parasitic nematodes. CAB International, Wallingford, UK. pp. $43-70$.

Jenkins, W.R., 1964. A rapid centrifugal-flotation technique for separating nematodes from soil. Pl. Dis. Rep. 48, 692.

Lazzeri, L., Curto, G., Leoni, O. \& Dallavalle, E., 2004a. Effects of glucosinolates and their enzymatic hydrolysis products via myrosinase on the root-knot nematode Meloidogyne incognita (Kofoid \& White). Chitw. Agric. Food Chem. 52, 6703-6707.

Lazzeri, L., Leoni, O. \& Manici, L.M., 2004b. Biocidal plant dried pellets for biofumigation. Ind. Crops and Prod. 20, 59-65.

Lazzeri, L., Tacconi, R. \& Palmieri, S., 1993. In vitro activity of some glucosinolates and their reaction products toward a population of nematode Heterodera schachtii. J. Agric. Food Chem. 41, 825-829.

Matthiessen, J.N. \& Kirkegaard, J.A., 2006. Biofumigation and enhanced biodegradation: Opportunity and challenge in soilborne pest and disease management. Crit. Rev. Plant Sci. 25, 235-265.

Mazzola, M., Brown, J., Izzo, A.D. \& Cohen, M.F., 2007. Mechanism of action and efficacy of seed meal-induced pathogen suppression differ in a Brassicaceae species and time-dependent manner. Ecol. and Epidemiol. 97, 454-460.

McKenry, M.V., 1992 (2 ${ }^{\text {nd }}$ ed). Nematodes. In: Flaherty, D.L., Christensen, L.P., Lanini, W.T., Marois, J.J., Phillips, P.A. \& Wilson, L.T. (eds). Grape pest management. Publication No. 3343. Division of Agricultural Science, University of California, Oakland, CA. pp. $281-293$.

McLeod, R.W. \& Steel, C.C., 1999. Effect of brassica-leaf green manures and crops on the activity and reproduction of Meloidogyne javanica. Nematol. 1, 613-624.

Melakeberhan, H., Xu, A., Kravchenko, A., Mennan, S. \& Rika, E., 2006. Potential use of aragula (Eruca sativa L.) as a trap crop for Meloidogyne hapla. Nematol. 8, 793-799.

Mojtahedi, H., Santo, G.S., Wilson, J.H. \& Hang, A.N., 1993. Managing Meloidogyne chitwoodi on potato with rapeseed as green manure. Plant Dis. 77, 42-46.

Munnecke, E.D. \& Van Gundy, D.S., 1979. Movement of fumigants in soil, dose response and differential effects. Phytopathol. 17, 405-429. 
Navon, A. \& Ascher, K.R.S., 2000. Bioassays of entomopathogenic microbes and nematodes. CAB International, Wallingford, UK.

Nusbaum, C.J. \& Ferris, H., 1973. The role of cropping systems in nematode population management. Ann. Rev. Phytopathol. 11, 423-440.

Nyczepir, A.P. \& Tomas, S.H., 2009. Current and future management strategies in intensive crop production systems. In: Perry, R.N., Moens, M. \& Starr, J.L. (eds). Root-knot nematodes. CABI, Wallingford, UK. pp. 412 -443 .

Nyczepir, A.P. \& Meyer, S.L.S., 2010. Host status of endophyte-infected and noninfected tall fescue grass to Meloidogyne spp. J. Nematol. 42, 151158 .

Nyczepir, A.P., Wood, B.W. \& Rieghard, G.L., 1997. Impact of Meloidogyne incognita on the incidence of peach tree short life in the presence of Criconmella xenoplax. J. Nematol. 29, 725-730.

Piedra Buena, A., Garcia-Alvarez, A., Diez-Rojo, M.A. \& Bello, A., 2006. Use of cover crop residues for the control of Meloidogyne incocnita under laboratory conditions. Pest Manag. Sci. 62, 919-926.

Piedra Buena, A., Garcia-Alvarez, A., Dies-Rojo, M.A., Ros, C., Fernadez, P. \& Lacasa, A., 2007. Use of pepper crop residues for the control of rootknot nematodes. Bioresource Technol. 98, 2846-2851.

Pieters, A.J., 2006. Green manuring: Principles and practices. Braunworth, New York.

Pinkerton, J.N., Schreiner, R.P., Ivors, K.L. \& Vasconcelos, M.C., 2004. Effects of Mesocriconema xenoplax on Vitis vinifera and associated mycorrhizal fungi. J. Nematol. 36, 193-201.

Ploeg, A.T. \& Stapleton, J.J., 2001. Glasshouse studies on the effect of time, temperature and amendment of soil with broccoli plant residues on the infestation of melon plants by Meloidogyne incocnita and M. javanica. Nematol. 3, 855-861.
Rahman, L, Weckert, M. \& Orchard, B., 2009. Effect of three consecutive annual applications of brassica green manures on root-knot nematode suppression in soil. Aust. N.Z. Grapegrow. Winemak. 37, 10-12.

Riga, E., 2011. The effect of Brassica green manures on plant parasitic and free living nematodes used in combination with reduced rates of synthetic nematicides. J. Nematol. 43, 119-121.

Riga, E. \& Collins, P., 2004. Green manure effects on Meloidogyne chitwoodi and Paratrichodorus allius, economically important nematodes of potatoes, in the Pacific Northwest of the USA. Agroindustria 3, 321-322.

Roubtsova, T., Lopez-Perez, J.A., Edwards, S. \& Ploeg, A., 2007. Effect of broccoli (Brassica oleracea) tissue, incorporated at different depths in a soil column, on Meloidogyne incognita. J. Nematol. 39, 111-117.

Sarwar, M., Kirkegaard, J.A., Wong, P.T.W. \& Desmarchelier, J.M., 1998. Biofumigation potential of brassicas. Plant \& Soil 201, 103-112.

StatSoft, Inc., 2011. STATISTICA (data analysis software system), version 10. www.statsoft.com.

Stirling, G.R. \& Stirling, A.M., 2003. The potential of brassica green manure crops for controlling root-knot nematode (Meloidogyne javanica) on horticultural crops in a subtropical environment. Aust. J. Exp. Agric. 43, 623-630.

Storey, S., 2007. Nematodes in vines. Practical guidelines for the short- and long-term control of nematodes. Wineland, 60-63.

Westphal, A., 2011. Sustainable approaches to the management of plantparasitic nematodes and disease complexes. J. Nematol. 43,122-125.

Widmer, T.L., Mitkowski, N.A. \& Abawi, G.S., 2002. Soil organic matter and management of plant-parasitic nematodes. J. Nematol. 34, 289-295. 